\title{
Chemical Functionalization of Exfoliated Graphene
}

Solon P. Economopoulos, ${ }^{[a]}$ and Nikos Tagmatarchis* ${ }^{[a]}$

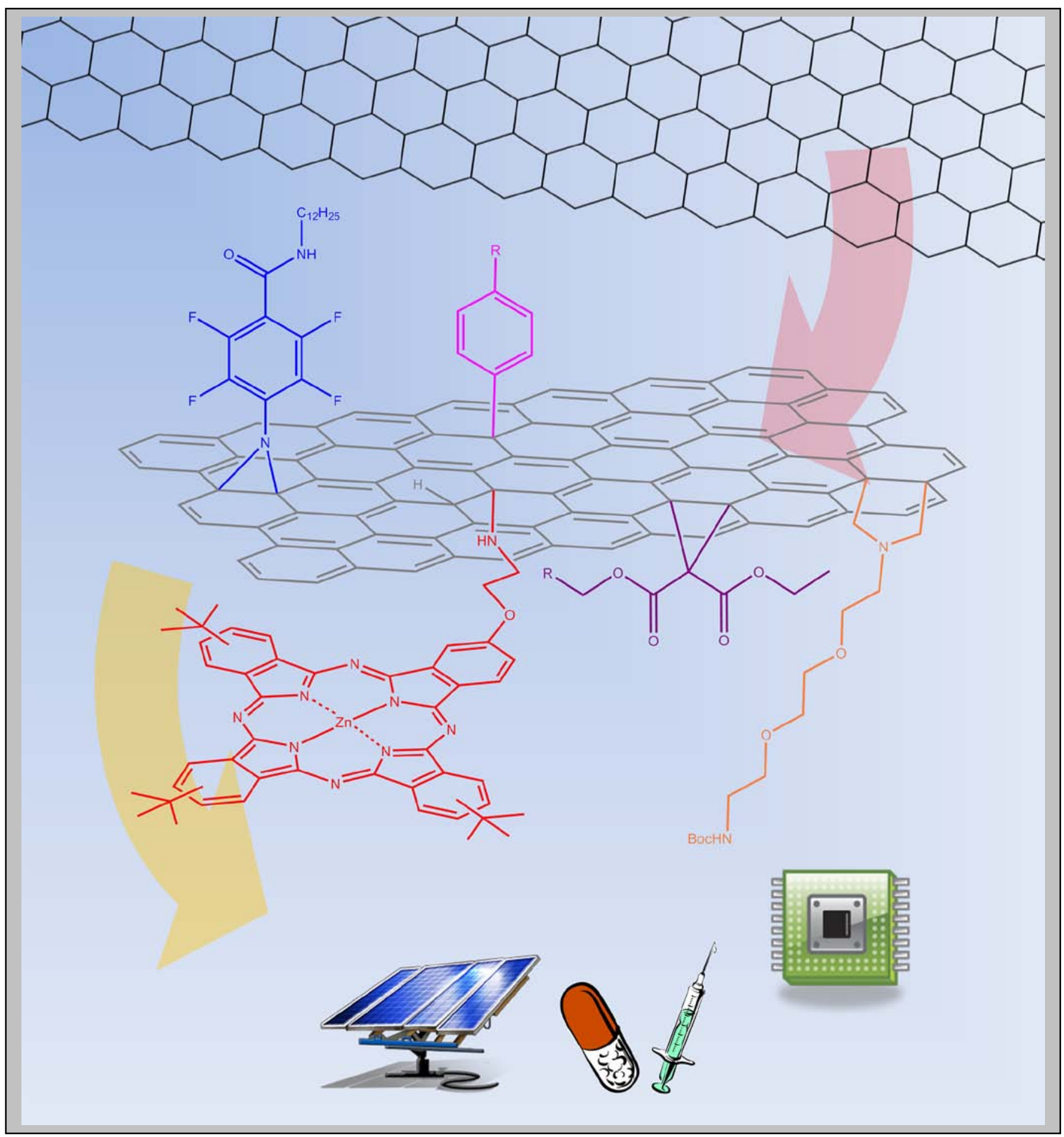


Abstract: Graphene is turning out to be the material that will effectively kick-start a new era for nanotechnology. The impressive properties of this atom-thick carbon layer are taking shape and form with early reports of successful applications based on it. The turning point for this material will be its low cost mass production. In this report a chemist's perspective on the production methods for graphene and the subsequent functionalization processes is discussed.

Keywords: graphene $\bullet$ exfoliation $\bullet$ functionalization • solubilization $\bullet$ hybrids

\section{Introduction}

The dynamic for nanotechnological applications utilizing graphene is hard to ignore, especially when compared to preceding carbon allotropes that have been around for more than 20 years. This promising material, isolated less than a decade ago, ${ }^{[1]}$ has sparked the imagination of researchers in numerous applications but, more importantly, has been successfully utilized in a large number of proof-of-concepts. Owed to its unique properties extending from mechanical ${ }^{[2]}$ to electrical ${ }^{[3]}$ the science revolving around graphene has rapidly moved along. As was the case with fullerenes, from their discovery in 1985 until their first reported synthetic process via the "Krätschmer-Huffman-Method", the general consensus, is that for every novel material, the high quality and supply of the material will ultimately define its widespread incorporation and success. The roadmap for this allotrope, undoubtedly, holds some important milestones for graphene-based devices, such as transistors, ${ }^{[4]}$ transparent electrodes for optoelectronics ${ }^{[5]}$ and biomedical applications. ${ }^{[6]}$ As recently, summarized by Novoselov et $a l,{ }^{[7]}$ an analysis on the quality vs cost plot was attempted for the various synthetic approaches for graphene production. ${ }^{[8]}$ Although progress is continually made across all fronts, even in processes like mechanical exfoliation, ${ }^{[9]}$ it is logical to assume that certain highcost high-quality graphene producing techniques are not suitable for supplying graphene for the purposes of e.g. synthesizing novel graphene-based materials via functionalization routes.

On the other hand, exfoliated graphene by wet chemistry, via oxidation under harsh conditions ${ }^{[10]}$ (using a modification of the Hummers method ${ }^{[11]}$ or other oxidizing agents ${ }^{[12]}$ ) results on graphene oxide (GO), however, with a disrupted electronic network deficient of novel electronic properties. As reduction of GO partially occurs, while sometimes leads to amorphous carbon, ${ }^{[13]}$ restoration of the $\mathrm{sp}^{2}$ network is incomplete and therefore the properties of the resulting reduced graphene oxide $(\mathrm{RGO})^{[14]}$ significantly deviate from those of pristine graphene. Along the same lines, milder liquid-phase approaches have been developed for exfoliating graphite upon (ultra)sonication, ${ }^{[15]}$ however, additives, that may interfere with graphene altering certain properties, are needed to prevent reaggregation.
On this mini-review we outline the routes of exfoliated graphene existing in the literature and the key functionalization processes linked to these routes. Only if graphene can be abundantly produced it may actively compete with silicon-based technology in electronic applications. Thus, the objective of this article is to highlight and summarize the facile ways for producing soluble graphene (or few-layer graphene) on the road to gramscale production and applications.

Solon P. Economopoulos obtained his BSc in Chemistry (2001) and his $\mathrm{PhD}$ (2006) in semiconducting polymer synthesis from the University of Patras, Greece. His research interests revolve around the broad field of organic photovoltaic materials, from synthesis and characterization of polymers to functionalization of fullerenes, carbon nanotubes and graphene. He was awarded a 3-year grant from the General Secretariat for Research and Technology and is currently involved in the synthesis of novel graphene donoracceptor hybrids at the National Hellenic Research Foundation.

Nikos Tagmatarchis is Director of Research in the Theoretical and Physical Chemistry Institute at the National Hellenic Research Foundation, in Athens, Greece. His research interests focus on the chemistry of carbon-based nanostructured materials in the context of electron transfer processes for diverse nanotechnological applications. His accomplishments in the area are reflected on a plethora of publications, citations and numerous invitations at conferences. He was recipient of the European Young Investigator Award (2004), Visiting Professor at the Chinese Academy of Sciences (2011) and Invited Fellow by the Japan Society for the Promotion of Science in Japan (2012).

\section{Exfoliated graphene sheets}

When discussing the prospect of chemically functionalizing graphene the most cost effective, facile and scalable approach appears to be the liquid-phase exfoliation of graphite. ${ }^{[16]}$ This route generally yields small graphene nanoparticles with sizes up to $\mu \mathrm{m}$ and with few-layered-graphene (FLG) as common "byproducts". This approach is, understandably, based on the ability to overcome the weak, but numerous Van der Waals attraction 
forces that are present between the graphitic layers. The primary focus is centered on the idea of selecting the appropriate exfoliating agent that will promote the exfoliation process. In general, these agents have been based on the "molecular wedge" approach. A planar molecule with the ability to create weak Van der Waals interactions with the graphitic lattice and overcome the existing ones between the neighboring graphene sheets in graphite. Initially this approach has generated interest due to its simplicity and scalability, however, the drawback is that the sonication applied in this process basically breaks the graphite flake into smaller particles that cannot "compete" with the graphene nanoparticle sizes produced by methods, such as mechanical exfoliation. However, these disadvantages simply place the produced graphene into different areas of nanotechnology, where smaller particle size is desirable. ${ }^{[7]}$ Finally, due to the fact that the exfoliation process is based on the breaking down of larger graphite flakes to smaller nanoparticles, it creates defect sites mostly around the edges of the formed nanosized flakes (Scheme $1)$.

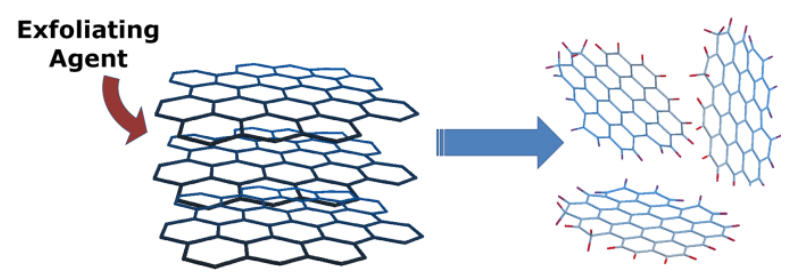

Scheme 1. Schematic representation of the exfoliation of graphite flakes producing exfoliated graphene. The red bonds on the exfoliated graphene denote the most probable defect sites where the $\mathrm{sp}^{2}$ hybridized carbon atoms of the graphene lattice have turned to $\mathrm{sp}^{3}$ hybridized atoms.

In order to effectively apply liquid-phase exfoliation to produce graphene, two distinct methods have been proposed: the use of surfactants and the use of exfoliating agents/solvents. Today, there is a multitude of both ionic and non-ionic surfactants that effectively produce stable graphene dispersions. ${ }^{[17]}$ The advantage of surfactants, besides their efficiency in the exfoliating process, revolves around the idea that the plethora of readily available molecules, as well as custom synthesized ones, guarantees solubility in either aqueous or organic solvents or even offering the prospect of switching solubility. ${ }^{[18]}$ Similarly to colloidal suspensions, the graphene layers coated with surfactants are stabilized against aggregation through electrostatic repulsion Coulombic forces. Moreover there are reliable techniques, such as centrifugation, that can provide high quality single layer graphene from these suspensions. ${ }^{[19]}$ In addition, depending on the surfactant, these products can provide the desired processability demanded by graphene-based applications. ${ }^{[20]}$ However, the surfactant-approach poses the problem of residual molecules between the graphene sheets that have been shown to affect the desired properties of the carbon nanomaterial. ${ }^{[21]}$ As expected, these non-covalently attached "impurities" can have a variety of undesirable effects throughout the spectrum of applications targeted by graphene. ${ }^{[22]}$ Furthermore, the removal of these residual molecules can prove to be a demanding task. ${ }^{[23]}$ To this end, a very recent breakthrough was made with the introduction of binol salt as an easily removable exfoliating agent. ${ }^{[24]}$

On the other hand, the route of using an exfoliating solvent/agent, although similar in nature to the surfactant approach, retains the advantage of utilizing a small molecule/solvent to achieve the desired dispersion that will, in principle, be easier to remove. Therein lays the fine line between using an exfoliating agent and non-covalent functionalization. Both approaches rely on the same principle, but the exfoliating agent is a medium required for facilitation of subsequent covalent or non-covalent functionalization, while the latter is the end-product. Having said that, it is not uncommon for non-covalent functionalization processes to also promote and improve exfoliation of graphene in organic dispersions. ${ }^{[25]}$ At present, several exfoliation-promoting agents producing graphene (or FLGs) from graphite have been proposed such as N-methyl pyrollidone (NMP), ${ }^{[15]}$ o-dichloro benzene (o-DCB), ${ }^{[26]}$ and benzylamine. ${ }^{[27]}$ Apart from these organic solvents, other exfoliating agents have been proposed such as the addition of sodium hydroxide ${ }^{[28]}$ or other sodium-based salts. ${ }^{[29]}$ These agents have been shown to produce stable dispersions for several days and depending on sonication time, power and workup process (centrifugation) they can produce mostly single layer graphene dispersions with concentrations approaching $1 \mathrm{mg} \mathrm{mL}^{-1}$, thus providing a solid basis for the supply of raw material required by chemists to promote graphene functionalization. It is worth noting that the use of o-DCB, a widely used dispersion agent aiding in the individualization of other carbon nanocomposites such as single-walled carbon nanotubes, has been known to undergo sonochemical decomposition and polymerization. Although the by-products of o-DCB can promote, and are possibly crucial to the stabilization of nanotube dispersions, ${ }^{[30]}$ researchers aiming to use this solvent with graphene should have in mind processes such as ultracentrifugation for the removal of the majority of o-DCB sonochemical by-products. ${ }^{[31]}$

\section{Covalent functionalization strategies for graphene}

On the subject of graphene functionalization, several excellent reports exist in the literature highlighting the strategies to covalently decorate graphene with functional groups. ${ }^{[32]}$ The functionalization of graphene follows, in large, the same principles as the ones laid down by fullerenes and nanotubes. The scientific community strives for continuous progress in the field ${ }^{[33]}$ and attempting to guide future synthetic efforts. ${ }^{[34]}$

Among the most popular covalent functionalization routes is the 1,3-dipolar cycloaddition reaction of in-situ generated azomethine ylides. ${ }^{[35]}$ Proposed by Prato and coworkers the reaction allows for the covalent functionalization of exfoliated graphene by in-situ generated azomethine ylides incorporating fused pyrrolidines onto the skeleton of graphene (Scheme 2). Moreover, the reaction has been shown to proceed with either NMP or dimethylformamide (DMF) as the exfoliating agent. ${ }^{[36]}$ The diversity of the produced materials offered by the careful selection of the aldehyde and $\alpha$-amino acid used for thermally generating the azomethine ylides is also noteworthy. In this context, donor-acceptor hybrids with porphyrin, ${ }^{[3]}$ and very recently phthalocyanine ${ }^{[38]}$ with exfoliated graphene have been successfully synthesized, opening up the route for energy harvesting applications. Furthermore, PAMAM dendrimers can also be covalently attached to the graphitic skeleton via the 1,3 dipolar cycloaddition reaction. ${ }^{[39]}$ In that same publication, Quintana et al took advantage of the carboxy defects created from the sonication process and situated mostly at the edges of the 
sheets to offer an alternative route to functionalize the graphene produced through peptide bond formation.

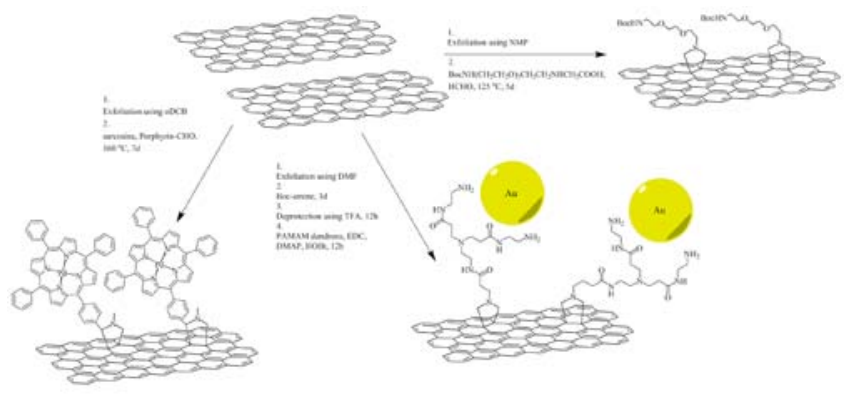

Scheme 2. Schematic representation of various 1,3-dipolar cycloaddition reactions of azomethine ylides for the functionalization of graphene sheets.

Azide chemistry has also been employed in graphene functionalization. Using o-DCB as the exfoliating agent, covalent attachment of perfluorophenylazides onto graphene has been achieved $^{[40]}$ (Scheme 3). The reaction is characterized by the transformation of the perfluoroazide to the singlet perfluoronitrene and its subsequent addition to the $\mathrm{sp}^{2}$ carbon. On a similar note, the aforementioned chemical process and its photo-reactivity driven mechanism was exploited to allow for graphene immobilization and patterning. The logic was to specifically anchor perfluoroazide functional groups on a substrate and then place highly oriented pyrolytic graphite onto them. The use of appropriate masking and subsequent photoirradiation to promote reactivity on the exposed surfaces, allowed for the removal of the unreacted graphite, resulting in single layer graphene immobilized on perfluorophenylazide sites. The induced electrical deterrence, in fabricated field effect transistors from the defects introduced by the functionalization process, was not notably high and the devices were comparable to mechanically exfoliated graphene sheets on $\mathrm{SiO}_{2}$ substrates. The azide chemistry also allows for anchoring of simple acetylene groups that can subsequently act as anchoring sites for any number of appropriately modified conjugated polymers, affording interesting donor-acceptor structures as Castelain et al recently demonstrated with the anchoring of polyfluorene onto graphene. ${ }^{[41]}$ Besides highly functionalized graphene by other aromatic azides, ${ }^{[42]}$ nitrene chemistry has also yielded polymer functionalized graphene. ${ }^{[43]}$

Exploiting the direct nucleophilic addition of primary amines to carbon nanostructured materials for the covalent functionalization of exfoliated graphene, Karousis and coworkers recently demonstrated electronic communication between photoreactive metallo-phthalocyanines and graphene sheets ${ }^{[44]}$ (Scheme 3). Besides the hybrid synthesized, their study involved an electrochemical solar cell prototype device fabrication. Although modest efficiency measurements ( $2 \%$ ) were reported, the authors noticed an almost ten-fold increase in incident photonto-current conversion efficiency compared to non-covalently attached Zn-phthalocyanine chromophores to graphenes. ${ }^{[45]}$

The Bingel cyclopropanation reaction has also been applied in our group, for graphene functionalization process, offering a simple and efficient route towards hybrids, soluble in common organic solvents. ${ }^{[27]}$ The moiety of benzylamine offers a solid basis for the exfoliation of graphene affording stable dispersions for several days. The concentration of the produced graphene dispersions is also among the highest reported in the literature, reaching up to $\sim 1 \mathrm{mg} \mathrm{mL}^{-1}$. With its relatively high boiling point, it is fairly challenging to remove traces of benzylamine after the exfoliation process, so annealing at $\sim 200{ }^{\circ} \mathrm{C}$ for $\mathrm{t}=1-2 \mathrm{~h}$ required. The Bingel reaction approach presented, offers the possibility of being microwave-activated, reducing the reaction time to minutes, a prospect of importance when industrial-scale applications are factored-in. In most of the functionalization approaches, the reaction times consist from several hours to days, while the microwave can essentially eliminate this factor. The reaction also exhibits tolerance to different malonates and can prove a useful tool for organic soluble graphene hybrids (Scheme 3).

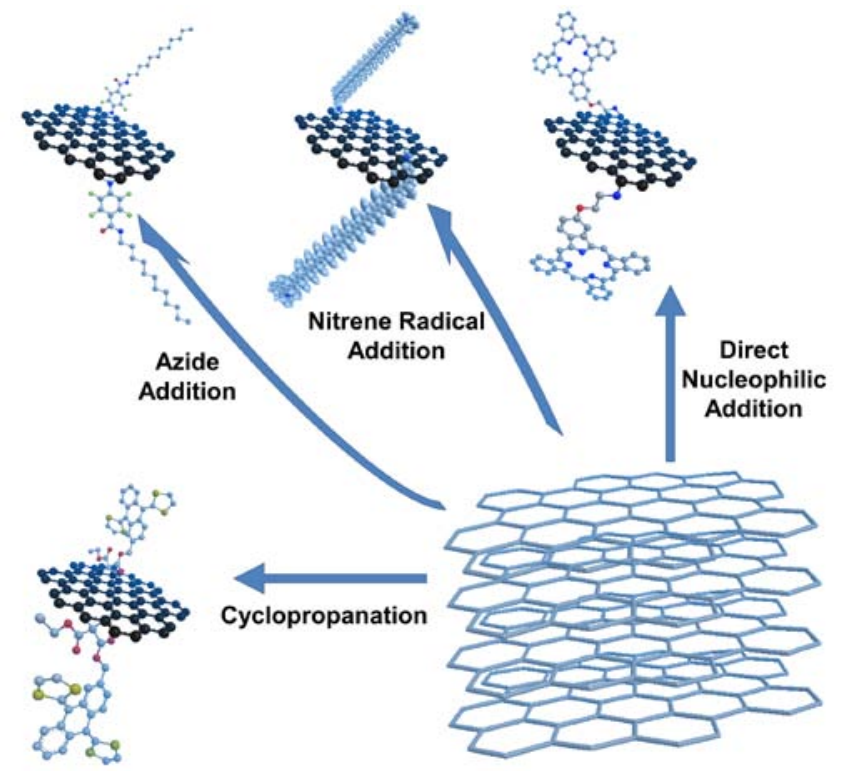

Scheme 3. Schematic representation of azide, nitrene and cyclopropanation routes affording functionalized graphene through exfoliation.

The aryl diazonium salt reaction represents another efficient way toward graphene functionalization ${ }^{[46]}$ (Scheme 4). The incorporation of bulky aryl moieties onto the basal plane of graphene facilitates steric repulsion between graphene layers, thus preventing reaggregation. ${ }^{[4]}$ Importantly, the functionalization degree of graphene can be modulated by the diazonium salt concentration, thus making possible to retain the novel electronic structure of graphene even after the covalent modification. Furthermore, the reaction has been tested with either graphene obtained from nanotube unzipping ${ }^{[48]}$ or through a reverse process employing mostly edge functionalization of expanded graphite and subsequent exfoliation and individualization of the graphene sheets, using DMF. ${ }^{[47]}$ It is worth mentioning that the chemical reactivity of aryl diazonium salts with graphene has been recently shown to be extremely preferential towards areas of graphene with higher curvature ${ }^{[49]}$ and to depend substantially on the number of graphene layers, ${ }^{[50]}$ thus allowing not only selective functionalization, but opening up possible routes towards surface patterning. This functionalization route has very recently been employed for the assembly of a molecular monolayer sandwiched between two graphene sheets, used as electrodes. ${ }^{[51]}$ The reaction has also shown potential as an intermediate step, allowing for post-functionalization processes onto the obtained aryl-modified graphene through "click chemistry", allowing enrichment of the decoration of the resulting product. ${ }^{[52]}$ Furthermore, the aryl 
diazonium salts strategy has been applied to functionalize exfoliated graphene obtained by reduction of graphite with $\mathrm{Na}-\mathrm{K}$ alloy $^{[53]}$ (Scheme 4). In the latter system, the intercalated metal cations neutralize the negatively charged graphene sheets, which are held apart with the aid of repulsive electrostatic forces. ${ }^{[54]}$

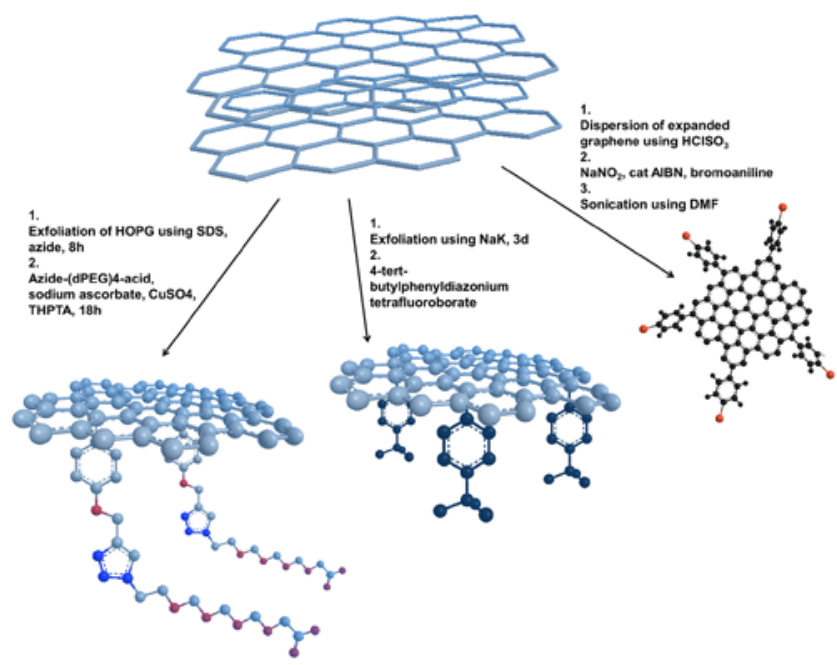

Scheme 4. Schematic representation of diazonium salt functionalization processes on graphene.

Finally, on a different route, the negatively charged graphene sheets, derived upon reduction of graphite with $\mathrm{Na}-\mathrm{K}$, have been trapped with hexyl iodide. ${ }^{[55]}$ This kind of functionalization, based on reductive alkylation of graphene, can potentially be utilized to get easy access to a new class of materials by simply quenching the negative charges on reduced graphene by diverse electrophiles.

\section{Summary and Outlook}

The diverse materials based on the covalent functionalization of graphene should be improved along two basic axes. First and foremost the scaling-up for the production methods should be considered. Liquid-phase exfoliation provides a facile way for obtaining high quality raw material improving upon the grapheneoxide approach. Optimizing yields and quantity/quality will most certainly allow for wider incorporation of the designed endproducts into applications. Secondly, although there have been reports where the exfoliating agent can be used to heal graphene defects, ${ }^{[56]}$ the removal efficiency of the agent used to provide the raw materials, (through exfoliation) should be revisited, as the residual products, in most cases, interfere with the target application.

The era of graphene-based applications is approaching fast, driven mostly for the need for novel materials. It is clear that the prospect of functionalizing graphene sheets caters to a wide category of applications that are not related to large uniform sheets of pristine graphene. Through chemical modification the excellent properties of pristine graphene sheets are indeed degraded, to some extent, but the improvements on processability aim to counter the shortcomings. The properties gained from the functionalization with various moieties, equips the materials industry with new hybrids suited from biomedicine and drug delivery to organic electronics, mechanical reinforcement additives and fuel cells. The key is to take advantage of scalable and facile routes towards functionalization and to be able to incorporate the best ideas of different approaches, on the way to the end-device.

\section{Acknowledgements}

Partial financial support from GSRT/NSRF 2007-2013 through action "Postdoctoral support” project GRAPHCELL PE5(2126) and by the Greek General Secretariat for Research and Technology and the European Commission, through the European Fund for Regional Development, NSRF 2007-2013 action "Development of Research

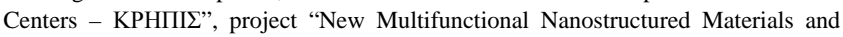
Devices - POLYNANO” is acknowledged.

[1] K. S. Novoselov, A. K. Geim, S. V. Morozov, D. Jiang, Y. Zhang, S. V. Dubonos, I. V. Grigorieva, A. A. Firsov, Science 2004, 306, 666-669.

[2] C. Lee, X. Wei, J. W. Kysar, J. Hone, Science 2008, 321, 385-388.

[3] X. Du, I. Skachko, A. Barker, E. Y. Andrei, Nature Nanotech. 2008, 3, 491495.

[4] Y. Wu, Y.-M. Lin, A. A. Bol, K. A. Jenkins, F. Xia, D. B. Farmer, Y. Zhu, P. Avouris, Nature 2011, 472, 74-78.

[5] K. S. Kim, Y. Zhao, H. Jang, S. Y. Lee, J. M. Kim, K. S. Kim, J.-H. Ahn, P. Kim, J.-Y. Choi, B. H. Hong, Nature 2009, 457, 706-710.

[6] a) N. Mohanty, V. Berry, Nano Lett. 2008, 8, 4469-4476; b) K. Yang, L. Feng, X. Shi, Z. Liu, Chem. Soc. Rev. 2013, 42, 530-547; c) C. Wang, J. Li, C. Amatore, Y. Chen, H. Jiang, X.-M. Wang, Angew. Chem., Int. Ed. 2011, 50, 11644-11648; d) L. Feng, L. Wu, X. Qu, Adv. Mater. 2013, 25, 168-186.

[7] K. S. Novoselov, V. I. Falko, L. Colombo, P. R. Gellert, M. G. Schwab, K. Kim, Nature 2012, 490, 192-200.

[8] a) C. Mattevi, H. Kim, M. Chhowalla, J. Mater. Chem. 2011, 21, 3324-3334; b) L. Jiao, L. Zhang, X. Wang, G. Diankov, H. Dai, Nature 2009, 458, 877880; c) D. V. Kosynkin, A. L. Higginbotham, A. Sinitskii, J. R. Lomeda, A. Dimiev, B. K. Price, J. M. Tour, Nature 2009, 458, 872-876; d) L. Chen, Y. Hernandez, X. Feng, K. Müllen, Angew. Chem. Int. Ed. 2012, 51, 7640-7654.

[9] J. Chen, M. Duan, G. Chen, J. Mater. Chem. 2012, 22, 19625-19628.

[10] a) D. R. Dryer, S. Park, C. W. Bielawski, R. S. Ruoff, Chem. Soc. Rev. 2010, 39, 228-240; b) D. Chen, H. Feng, J. Li, Chem. Rev. 2012, 112, 6027-6053.

[11] W. S. Hummers, R. E. Offeman, J. Am. Chem. Soc. 1958, 80, 1339-1339.

[12] W. Lu, S. Liu, X. Qin, L. Wang, J. Tian, Y. Luo, A. M. Asiri, A. O. Al-Youbi, X. Sun, J. Mater. Chem. 2012, 22, 8775-8777.

[13] W. Gao, L. B. Alemany, L. Ci, P. M. Ajayan, Nature Chem. 2009, 1, 403-408.

[14] I. K. Moon, J. Lee, R. S. Ruoff, H. Lee, Nat. Commun. 2010, 1, 73.

[15] Y. Hernandez, V. Nicolosi, M. Lotya, F. M. Blighe, Z. Sun, S. De, I. T. McGovern, B. Holland, M. Byrne, Y. K. Gun'Ko, J. J. Boland, P. Niraj, G. Duesberg, S. Krishnamurthy, R. Goodhue, J. Hutchison, V. Scardaci, A. C. Ferrari, J. N. Coleman, Nature Nanotech. 2008, 3, 563-568.

[16] J. N. Coleman, Acc. Chem. Res. 2012, 46, 14-22.

[17] L. Guardia, M. J. Fernández-Merino, J. I. Paredes, P. Solís-Fernández, S. Villar-Rodil, A. Martínez-Alonso, J. M. D. Tascón, Carbon 2011, 49, 16531662.

[18] T. Skaltsas, N. Karousis, H.-J. Yan, C.-R. Wang, S. Pispas, N. Tagmatarchis, J. Mater. Chem. 2012, 22, 21507-21512.

[19] A. A. Green, M. C. Hersam, Nano Lett. 2009, 9, 4031-4036.

[20] a) Y. T. Liang, M. C. Hersam, J. Am. Chem. Soc. 2010, 132, 17661-17663; b) J. H. Lee, D. W. Shin, V. G. Makotchenko, A. S. Nazarov, V. E. Fedorov, Y. H. Kim, J.-Y. Choi, J. M. Kim, J.-B. Yoo, Adv. Mater. 2009, 21, 4383-4387; c) M. Lotya, P. J. King, U. Khan, S. De, J. N. Coleman, ACS Nano 2010, 4, 3155-3162; d) D. Parviz, S. Das, H. S. T. Ahmed, F. Irin, S. Bhattacharia, M. J. Green, ACS Nano 2012, 6, 8857-8867.

[21] C.-J. Shih, G. L. C. Paulus, Q. H. Wang, Z. Jin, D. Blankschtein, M. S. Strano, Langmuir 2012, 28, 8579-8586. 
[22] D. A. C. Brownson, J. P. Metters, D. K. Kampouris, C. E. Banks, Electroanalysis 2011, 23, 894-899.

[23] M. Lotya, Y. Hernandez, P. J. King, R. J. Smith, V. Nicolosi, L. S. Karlsson, F. M. Blighe, S. De, Z. Wang, I. T. McGovern, G. S. Duesberg, J. N. Coleman, J. Am. Chem. Soc. 2009, 131, 3611-3620.

[24] S. Some, Y. Kim, E. Hwang, H. Yoo, H. Lee, Chem. Commun. (Cambridge, U. K.) 2012, 48, 7732-7734.

[25] N. V. Kozhemyakina, J. M. Englert, G. Yang, E. Spiecker, C. D. Schmidt, F. Hauke, A. Hirsch, Adv. Mater. 2010, 22, 5483-5487.

[26] C. E. Hamilton, J. R. Lomeda, Z. Sun, J. M. Tour, A. R. Barron, Nano Lett. 2009, 9, 3460-3462.

[27] S. P. Economopoulos, G. Rotas, Y. Miyata, H. Shinohara, N. Tagmatarchis, ACS Nano 2010, 4, 7499-7507.

[28] W. W. Liu, J. N. Wang, Chem. Commun. (Cambridge, U. K.) 2011, 47, 68886890.

[29] W. Du, J. Lu, P. Sun, Y. Zhu, X. Jiang, Chem. Phys. Lett. 2013, 568-569, 198-201.

[30] S. Niyogi, M. A. Hamon, D. E. Perea, C. B. Kang, B. Zhao, S. K. Pal, A. E. Wyant, M. E. Itkis, R. C. Haddon, J. Phys. Chem. B 2003, 107, 8799-8804.

[31] D. S. Kim, D. Nepal, K. E. Geckeler, Small 2005, 1, 1117-1124.

[32] a) C. K. Chua, M. Pumera, Chem. Soc. Rev. 2013; b) L. Rodriguez-Perez, M. A. Herranz, N. Martin, Chem. Commun (Cambridge, U. K.) 2013, 49, 37213735; c) M. Quintana, E. Vazquez, M. Prato, Acc. Chem. Res. 2013, 46, 138148; d) J. Park, M. Yan, Acc. Chem. Res. 2013, 46, 181-189.

[33] a) N. Karousis, S. Economopoulos, N. Tagmatarchis, in Handbook of Carbon Nano Materials: Materials and Fundamental Applications, Vol. 4 (Eds.: F. D'Souza, K. M. Kadish), pp. 1-54; b) V. Georgakilas, M. Otyepka, A. B. Bourlinos, V. Chandra, N. Kim, K. C. Kemp, P. Hobza, R. Zboril, K. S. Kim, Chem. Rev. (Washington, DC, U. S.) 2012, 112, 6156-6214; c) A. Hirsch, J. M. Englert, F. Hauke, Acc. Chem. Res. 2013, 46, 87-96.

[34] Y. T. Liang, M. C. Hersam, Macromol. Chem. Phys. 2012, 213, 1091-1100.

[35] M. Quintana, K. Spyrou, M. Grzelczak, W. R. Browne, P. Rudolf, M. Prato, ACS Nano 2010, 4, 3527-3533.

[36] M. Quintana, E. Vazquez, M. Prato, Acc. Chem. Res. 2012, 46, 138-148.

[37] X. Zhang, L. Hou, A. Cnossen, A. C. Coleman, O. Ivashenko, P. Rudolf, B. J. van Wees, W. R. Browne, B. L. Feringa, Chem.-Eur. J. 2011, 17, 8957-8964.

[38] M.-E. Ragoussi, J. Malig, G. Katsukis, B. Butz, E. Spiecker, G. de la Torre, T. Torres, D. M. Guldi, Angew. Chem. Int. Ed. 2012, 51, 6421-6425.

[39] M. Quintana, A. Montellano, A. E. del Rio Castillo, G. V. Tendeloo, C. Bittencourt, M. Prato, Chem. Commun. (Cambridge, U. K.) 2011, 47, 93309332.

[40] L.-H. Liu, M. Yan, J. Mater. Chem. 2011, 21, 3273-3276.

[41] M. Castelaín, G. Martínez, P. Merino, J. Á. Martín-Gago, J. L. Segura, G. Ellis, H. J. Salavagione, Chem.-Eur. J. 2012, 18, 4965-4973.
[42] T. A. Strom, E. P. Dillon, C. E. Hamilton, A. R. Barron, Chem. Commun. (Cambridge, U. K.) 2010, 46, 4097-4099.

[43] X. Xu, Q. Luo, W. Lv, Y. Dong, Y. Lin, Q. Yang, A. Shen, D. Pang, J. Hu, J. Qin, Z. Li, Macromol. Chem. Phys. 2011, 212, 768-773.

[44] N. Karousis, J. Ortiz, K. Ohkubo, T. Hasobe, S. Fukuzumi, Á. Sastre-Santos, N. Tagmatarchis, J. Phys. Chem. C 2012, 116, 20564-20573.

[45] J. Malig, N. Jux, D. Kiessling, J.-J. Cid, P. Vázquez, T. Torres, D. M. Guldi, Angew. Chem., Int. Ed. 2011, 50, 3561-3565.

[46] E. Bekyarova, M. E. Itkis, P. Ramesh, C. Berger, M. Sprinkle, W. A. de Heer, R. C. Haddon, J. Am. Chem. Soc. 2009, 131, 1336-1337.

[47] Z. Sun, S.-i. Kohama, Z. Zhang, J. Lomeda, J. Tour, Nano Res. 2010, 3, 117125 .

[48] A. Sinitskii, A. Dimiev, D. A. Corley, A. A. Fursina, D. V. Kosynkin, J. M. Tour, ACS Nano 2010, 4, 1949-1954.

[49] Q. Wu, Y. Wu, Y. Hao, J. Geng, M. Charlton, S. Chen, Y. Ren, H. Ji, H. Li, D. W. Boukhvalov, R. D. Piner, C. W. Bielawski, R. S. Ruoff, Chem. Commun. (Cambridge, U. K.) 2013, 49, 677-679.

[50] R. Sharma, J. H. Baik, C. J. Perera, M. S. Strano, Nano Lett. 2010, 10, 398405.

[51] S. Seo, M. Min, S. M. Lee, H. Lee, Nat. Commun. 2013, 4, 1920.

[52] Z. Jin, T. P. McNicholas, C.-J. Shih, Q. H. Wang, G. L. C. Paulus, A. J. Hilmer, S. Shimizu, M. S. Strano, Chem. Mater. 2011, 23, 3362-3370.

[53] J. M. Englert, C. Dotzer, G. Yang, M. Schmid, C. Papp, J. M. Gottfried, H.-P. Steinrück, E. Spiecker, F. Hauke, A. Hirsch, Nature Chem. 2011, 3, 279-286.

[54] a) A. Catheline, C. Drummond, H. Saadaoui, C. A. Furtado, M. He, O. Roubeau, L. Ortolani, M. Monthioux, A. Penicaud, J. Am. Chem. Soc. 2008, 130, 1802-15804; b) A. Catheline, C. Valles, C. Drummond, L. Ortolani, V. Morandi, M. Marcaccio, M. Iurlo, F. Paolucci, A. Penicaud, Chem. Commun. (Cambridge, U. K.) 2011, 47, 5470-5472; c) K. F. Kelly, W. E. Billups, Acc. Chem. Res. 2013, 46, 4-13; d) A. Penicaud, C. Drummond, Acc. Chem. Res. 2013, 46, 129-137.

[55] J. M. Englert, K. C. Knirsch, C. Dotzer, B. Butz, F. Hauke, E. Spieckerb, A. Hirsch, Chem. Commun. (Cambridge, U. K.) 2012, 48, 5025-5027.

[56] M. Zhang, R. R. Parajuli, D. Mastrogiovanni, B. Dai, P. Lo, W. Cheung, R. Brukh, P. L. Chiu, T. Zhou, Z. Liu, E. Garfunkel, H. He, Small 2010, 6, 11001107.

Received: ((will be filled in by the editorial staff))

Revised: ((will be filled in by the editorial staff)) Published online: ((will be filled in by the editorial staff))

[a] Dr. S. P. Economopoulos, and Dr. N. Tagmatarchis

Theoretical and Physical Chemistry Institute

National Hellenic Research Foundation

48 Vassileos Constantinou Avenue, Athens 11635, Greece

Fax: (+) 302107273794

E-mails: economop@eie.gr (S. P. Economopoulos); tagmatar@eie.gr (N.

Tagmatarchis) 
Entry for the Table of Contents

Divide, functionalize and conquer

Solon P. Economopoulos*, Nikos

Tagmatarchis* Page-Page

Chemical Functionalization of Exfoliated Graphene

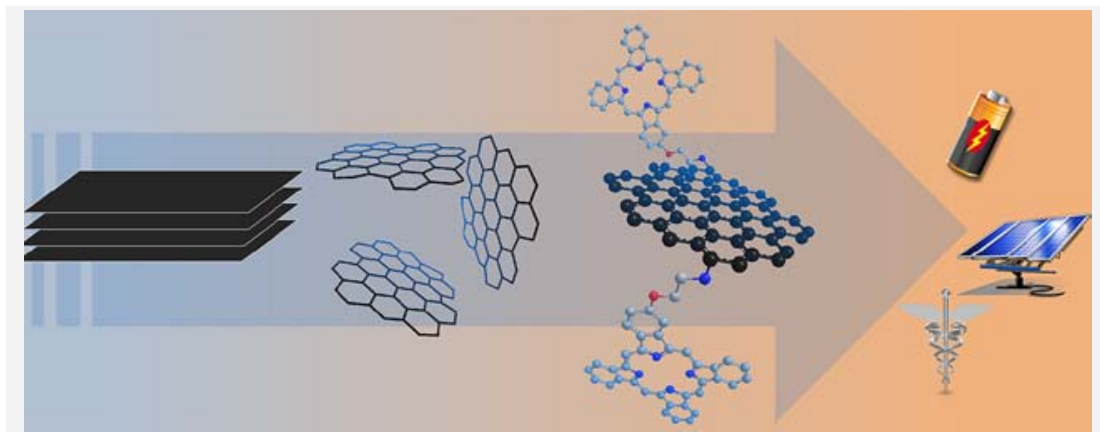

The key for graphene's widespread adoption seems to lie into the need for facile and cost-effective mass production. For material scientists, it is also important to chemically modify it, thus enriching its properties.
A summary of the most widely-used exfoliation and covalent functionalization methods on the road from graphite flakes to graphene hybrid materials is presented. 